\title{
Paternal origin of the de novo deleted chromosome 4 in Wolf-Hirschhorn syndrome
}

Rossella Tupler, Livio Bortotto, Erica M Bühler, Muallâ Alkan, Naseem J Malik, Nemya Bösch-Al Jadooa, Luigi Memo, Paola Maraschio

\begin{abstract}
The parental origin of the de novo deleted chromosome 4 was studied in five cases of Wolf-Hirschhorn syndrome using polymorphic probes mapping in the $4 \mathrm{p} 16.3$ region. In all the patients the deleted chromosome was found to be of paternal origin and these results, together with similar ones obtained by another group, make the preferential paternal origin of the de novo chromosome 4 deletion highly significant.
\end{abstract}

The parental origin of numerical and structural chromosome anomalies has been difficult to assess for years. Acrocentric chromosome polymorphisms, heterochromatic variants, and specific genetic markers are only occasionally informative.

Current DNA techniques provide a more precise means for studying the origin of chromosomal anomalies in man and recently several studies have indicated the possible existence of genomic imprinting, a phenomenon first discovered in the mouse (see Hall ${ }^{1}$ for a review).

The Wolf-Hirschhorn syndrome (WHS), characterised by low birth weight, developmental delay, microcephaly, hypertelorism, downward slanting palpebral fissures, prominent glabella, short philtrum, cleft lip and palate, low set, abnormal ears, and other possible abnormalities such as seizures and genital defects, results from monosomy of the distal short arm of chromosome $4 .^{2}$ Most cases are sporadic.

Table Clinical findings.

M Alkan

N J Malik

N Bösch-Al Jadooa

Laboratorio di

Citogenetica, Istituto

Immunotrasfusionale,

Ospedale Civile di

Udine, Italy.

L Bortotto

Div Pediatria,

Ospedale Civil

Treviso, Italy.

L Memo

Biologia Generale e Genetica Medica,

Università di Pavia, CP 217, 27100 Pavia,

Italy.

P Maraschio

Correspondence to Dr Maraschio.

Received 25 March 1991 Revised version accepted 28 May 1991.
We studied the parental origin of the deleted chromosome 4 in five patients with the WHS using probes mapping in the 4 p16.3 region.

\section{Materials and methods}

Sex, age, and clinical data of the five patients are shown in the table. All five patients had severely delayed growth, profound mental retardation, Greek warrior helmet face, and recurrent convulsive attacks.

Chromosome preparations were made from cultures of blood lymphocytes and high resolution banding was obtained according to Dutrillaux and Viegas-Pequignot. ${ }^{3}$

DNA was extracted directly from blood lymphocytes. For RFLP detection, $2 \mu \mathrm{g}$ of each DNA sample was digested to completion with the appropriate restriction enzyme $(A c c \mathrm{I}$, PstI, PvuII) as recommended by the supplier (Boehringer, Mannheim). The resultant DNA fragments were resolved according to size by agarose gel electrophoresis in TAE buffer. The DNA fragments in the gel were denatured in situ with $0.2 \mathrm{~mol} / 1 \mathrm{NaOH}, 0.6 \mathrm{~mol} / 1 \mathrm{NaCl}$. The denatured DNA fragments were transferred to a nylon filter (Hybond N-Amersham) by Southern blotting and fixed by UV.

DNA probes (pBS674E-D, 252-3, and D5 corresponding to D4S95, D4S115, and $D 4 S 90$, respectively) were labelled with $\left({ }^{32} \mathrm{P}\right)-$ dCTP (Amersham) by random oligonucleotide priming ${ }^{4}$ and then hybridised to the filter for 20 hours at $44^{\circ} \mathrm{C}$ in $50 \%$ formamide, $5 \times$ SSC, $1 \times$ Denhardt's solution, $20 \mathrm{mmol} / 1 \mathrm{NaH}_{2} \mathrm{PO}_{4}$, $10 \% \mathrm{Na}$ dextran sulphate, $0 \cdot 1 \% \mathrm{SDS}$, and $100 \mu \mathrm{g} / \mathrm{ml}$ of salmon sperm DNA. The filters

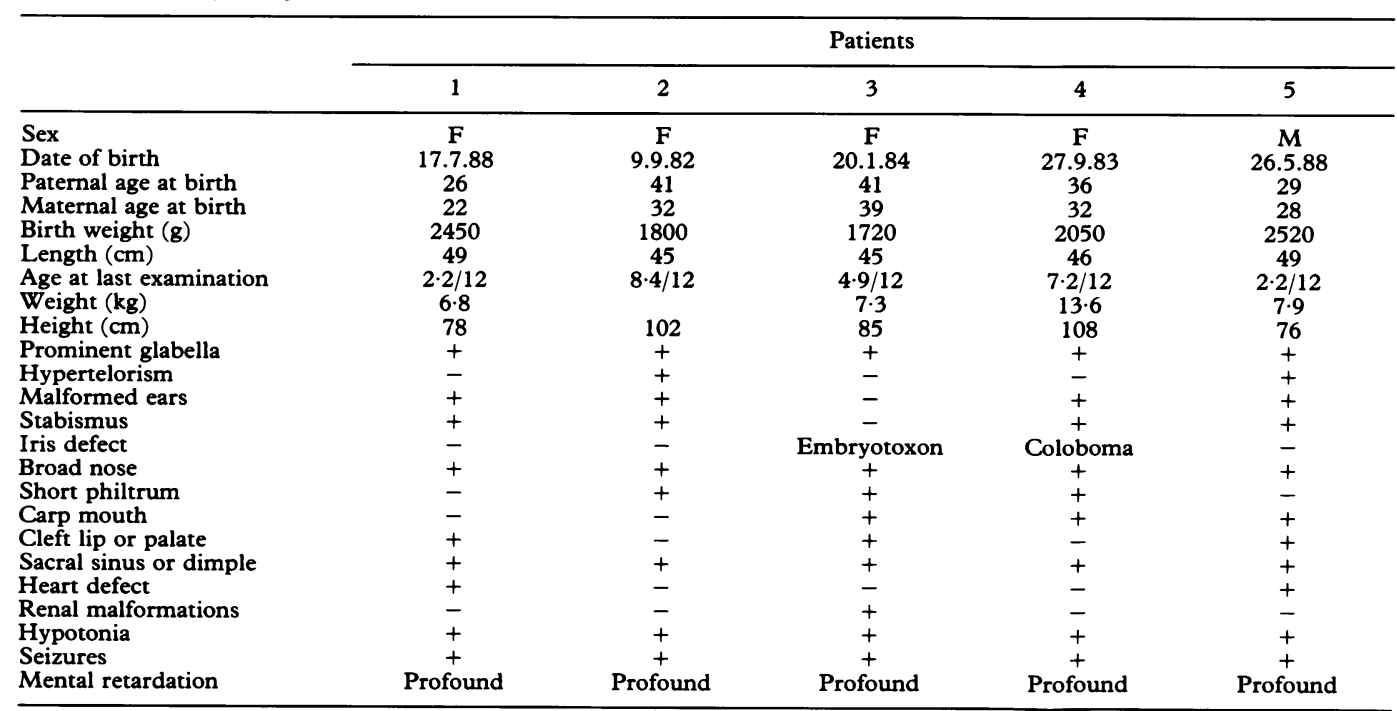


were washed twice in $2 \times \mathrm{SSC}$ at $44^{\circ} \mathrm{C}$ for 15 minutes, and once in $2 \times \mathrm{SSC}$ at $60^{\circ} \mathrm{C}$ for 15 minutes before autoradiography.

\section{Results}

In patients $1,2,3$, and 4 chromosome analysis showed a deletion of the region 4 p15.3 $\rightarrow 4$ pter. In patient 5 the abnormal chromosome 4 was derived from a translocation with a pericentromeric region of an acrocentric chromosome as indicated by the presence of the nucleolar organiser region. DA-DAPI staining, specific for chromosome 15, was negative. The monosomy of patient 5 included the region 4 p16.1 $\rightarrow$ pter. The parents of the patients all had normal karyotypes.

Molecular studies were performed using probes pBS674E-D, 252-3, and D5 which are localised in $4 \mathrm{p} 16.3$ distal to $D 4 S 10 .^{5}$

RFLP analysis of pBS674E-D (D4S95), hybridised with a filter of genomic DNA digested by $A c c \mathrm{I}$, showed the paternal origin of the deleted chromosome 4 in patients 2 and 5 (fig 1).

RFLP analysis of 252-3 (D4S115), hybridised with a filter of genomic DNA

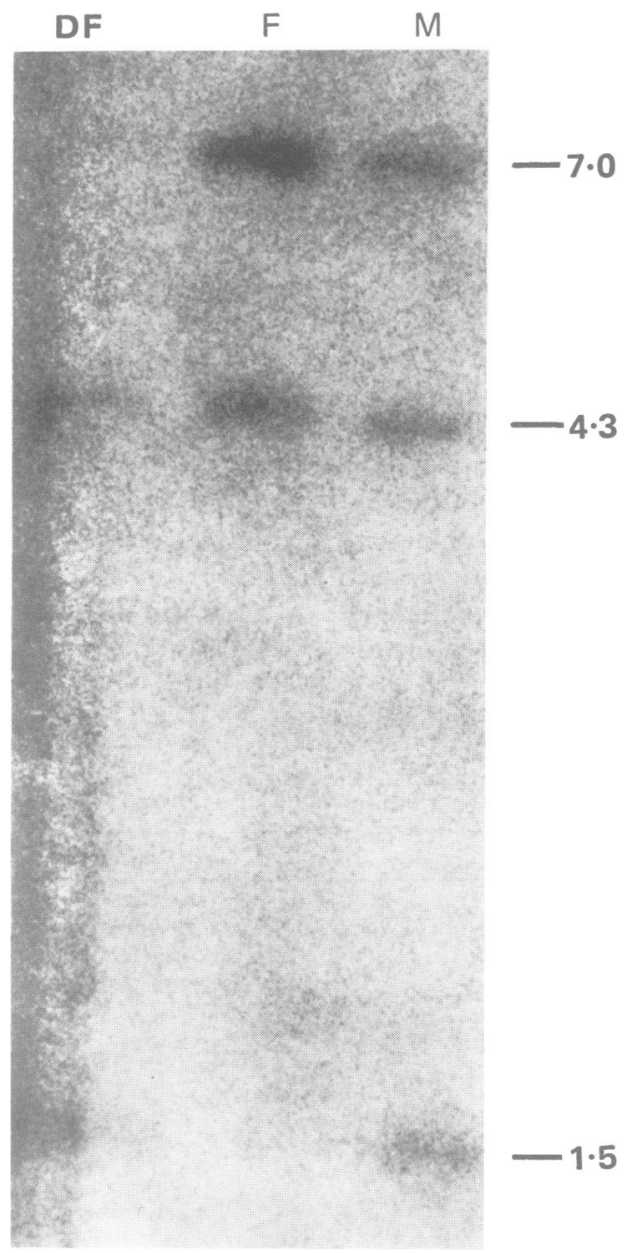

Figure 1 RFLP analysis of the $p B S 674 E-D$ probe (D4S95), hybridised with a filter of genomic DNA digested by AccI, of patient 5 (DF), his father (F), and mother $(M)$. The probe recognises two groups of polymorphic alleles of 7.0 and $1.5 \mathrm{~kb}$ and of $4.4,4.3$, $4 \cdot 2$, and $4 \cdot 1 \mathrm{~kb}$, respectively. In the proband only the maternal $1.5 \mathrm{~kb}$ allele is present while the paternal $7.0 \mathrm{~kb}$ allele is absent. digested by Pst $\mathrm{I}$, showed the paternal origin of the deleted chromosome 4 in patients $1,2,3$, and 4 (fig 2).

The paternal origin of the deleted chromosome 4 in patients 3 and 4 was confirmed by the RFLP analysis of D5 (D4S90), hybridised with genomic DNA digested by PvuII (fig 3).

\section{Discussion}

All our patients showed a de novo terminal deletion of the short arm of chromosome 4 including the region $4 \mathrm{p} 15.3 \rightarrow$ pter. In patient 5 monosomy $4 \mathrm{p} 16.1 \rightarrow \mathrm{pter}$ was the result of a de novo unbalanced translocation with an unidentified acrocentric chromosome. Our results are in agreement with previous reports suggesting that monosomy $4 \mathrm{p} 16$ is sufficient for the full expression of the Wolf-Hirschhorn syndrome, ${ }^{6}$ whose locus should be distal to D4S10. ${ }^{7}$ The paternal origin of the abnormal chromosome has been shown for all of our five patients using probes mapping in the deleted region.

Quarrell et $a l^{8}$ reported seven WHS patients with de novo deletions or rearrangements of the short arm of chromosome 4 showing paternal origin of the abnormal chromosome. Pooling our data and those of Quarrell et al, ${ }^{8}$ the preferential paternal origin of the de novo chromosome anomaly is significant $(0.02<\mathrm{p}<0.01)$.

A chromosome imprinting effect may account for these results. The best known imprinting effect in man is related to the deletion of band q11-q13 of chromosome 15. The same deletion causes Angelman's syndrome if the deleted chromosome is of maternal origin
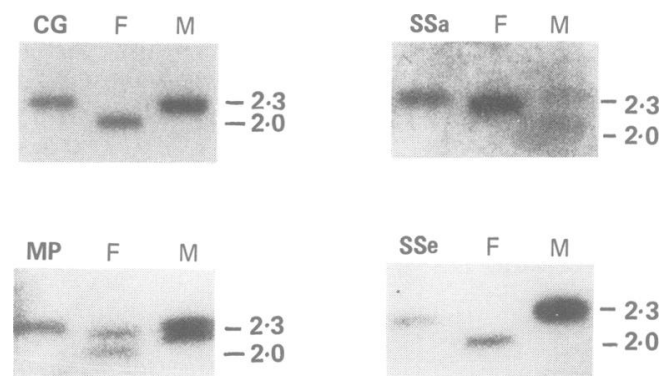

Figure 2 RFLP analysis of the 252-3 probe (D4S115), hybridised with a filter of genomic DNA digested by PstI, of patients 1 (CG), 2 (SSa), 3 $(S S e), 4(M P)$, and their parents $(F=$ father, $M=$ mother . The 252-3 probe recognises more than six alleles between $2 \cdot 2$ and $2 \cdot 6 \mathrm{~kb}$. In all four patients only the maternal allele is present.

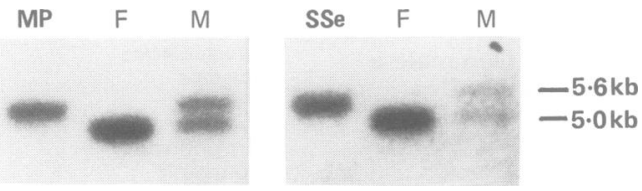

Figure 3 RFLP analysis of probe D5 (D4S90) hybridised with genomic DNA digested by PvuII, of patients 3 (SSe) and $4(M P)$ and their parents ( $F=$ father, $M=$ mother). The probe recognises two alleles of 5.0 and $5.6 \mathrm{~kb}$. Only the maternal $5.6 \mathrm{~kb}$ allele is present in the two patients. 
and the Prader-Willi syndrome if the deleted chromosome is of paternal origin. ${ }^{9}$

The deletion of the paternal chromosome 4 and maternal hemizygosity for the same region would be responsible for the expression of the WHS. We can postulate that the maternal origin of the chromosomal anomaly remains undetected, being either lethal in the embryo or without phenotypic effect.

However, the observation that patients with derivative $4 \mathrm{p}$ monosomy owing to familial translocation always show the WHS, irrespective of the parental origin of the anomaly, is against this hypothesis. In a review of published reports, Narahara et al $^{6}$ found that $13 \%$ of the $4 \mathrm{p}$ monosomies associated with WHS were the result of familial translocation. Among the 15 cases reported, five were of paternal and 10 of maternal origin.

It seems, therefore, that among these cases there was no selection against the deletions of the short arm of chromosome 4 of maternal origin and that the paternal chromosome 4 could be more prone to mutational events than the maternal one.

A similar discrepancy in the parental origin between familial and sporadic cases has been found in Beckwith-Wiedemann syndrome with an excess of maternal transmission in the former and paternal transmission in sporadic cases with chromosome $11 \mathrm{p} 15.1$ duplication. ${ }^{10}$

An imprinting phenomenon also related to chromosome 4 has been postulated to play some role in the expression of Huntington's disease (HD). The paternal transmission of the $\mathrm{HD}$ gene is correlated with an earlier onset and a more severe expression of the disease. ${ }^{11}$ Thus, it could be suggested that the distal region of the short arm of chromosome 4 in man is likely to undergo genomic imprinting. In the mouse, the region corresponding to the distal portion of $4 p$ in man does not appear to be subject to imprinting. ${ }^{111}$

Finally, it must be noted that the ratio between male and female WHS patients is $1: 2$. A distorted sex ratio has been observed in several chromosomal anomalies and is usually interpreted as resulting from differential survival in one sex. It is conceivable that the imprinting phenomenon may be responsible for the sex ratio distortion.

The authors are grateful to J F Gusella and J J Wasmuth and to $S$ Youngman and D J Shaw for providing probes, and to $G$ Camerino and L Tiepolo for their help in the preparation of this paper. RT was supported by the Rusconi Foundation, Varese.

1 Hall JG. Genomic imprinting: review and relevance to human disease. Am f Hum Genet 1990;46:857-73.

2 Buyse ML. Birth defects encyclopedia. New York: Center for Birth Defects Information Services, 1990.

3 Dutrillaux B, Viegas-Pequignot E. High resolution R and G banding on the same preparation. Hum Genet 1981;57:93-
band 5 .

4 Feinberg A, Vogelstein B. A technique for radiolabeling DNA restriction endonuclease fragments to high specific activity. Anal Biochem 1983;132:6-13.

5 Murray JC, Van Ommen JC. Report of the committee on the genetic constitution of chromosome 4. HGM 10.5 . Cytogenet Cell Genet 1990;55:97-110.

6 Narahara K, Himoto Y, Yokoyama Y, et al. The critical monosomic segment involved in $4 \mathrm{p}$ - syndrome: a high resolution banding study of five inherited cases. $\mathfrak{f p}_{p m}$ Hum Genet 1984;29:403-13.

7 McKeown C, Read P, Dodge A, et al. Wolf-Hirschhorn locus is distal to $D 4 S 10$ on short arm of chromosome $4 . \mathcal{F}$ Med Genet 1987;24:410-12.

8 Quarrell OWJ, Snell RG, Curtis MA, Roberts SH, Harper PS, Shaw DJ. Paternal origin of the chromosomal deletion resulting in the Wolf-Hirschhorn syndrome. $\mathcal{F ~ M e d}$ Genet 1991;28:256-9.

9 Magenis RE, Toth-Fejel S, Allen LJ, et al. Comparison of the 15q deletions in Prader-Willi and Angelman syndromes: specific regions, extent of deletions, parental origin and clinical consequences. Am $\mathcal{f}$ Med Genet 1990;35:333-49.

10 Reik W. Genomic imprinting and genetic disorders in man. Trends Genet 1989;5:331-6.

11 Reik W. Genomic imprinting: a possible mechanism for the parental origin effect in Huntington's chorea. $f \mathrm{Med}$ Genet 1988;25:805-8. 